\title{
Housing the Information Explosion
}

The National Reference Library of Science and Invention enters a new phase next week with the opening to the public of a large extension in Bayswater. Situated in Porchester Gardens, just off Queensway, the extension will complement the Holborn Division formerly known as the Patent Office Library. From October 29, biologists and other members of the public will have access to about 10,000 different periodicals and 18,000 books (excluding student texts) on all branches of the life sciences, and some physical subjects not covered at Holborn. The Holborn Division itself has about 17,000 periodical titles, and the two divisions together now offer an almost complete collection of modern scientific and technical literature, available to anyone for reference without a ticket.

All that is now wanting is a new building to hold both collections and the British Museum library as one multidisciplinary national reference library. The staff of the NRLSI are optimistic enough to call the Bayswater Division "temporary", although how long they will have to wait for a new building is anybody's guess. The staff have had to make the best they can out of two floors above a department store. It is for this reason that most of the material there is not so easily available as it is at Holborn. Key reference books, abstracting and indexing journals, and catalogues can bo consulted in the reading room, but books and periodicals have to be brought from shelves behind the scenes by the library staff. The staff say this will take only a few minutes. There are several catalogues -subject, author and periodical title, for example-to help readers who do not know quite what to ask for. In addition there are the same services as at Holborn- a rapid photocopy service, telex, and linguistic help with Russian and German. Practical details include seats for thirty-one readers in the reading room-more will be put in if necessary-an enquiry desk, and the help of a staff of science graduates. Opening hours at Bayswater are short at present, $10.0 \mathrm{am}-4.0 \mathrm{pm}$ (the Holborn Division is open from $9.30 \mathrm{am}$ to $9.0 \mathrm{pm}$ ).

There is some overlap in the stock of the two divisions. For example, bibliographical tools like Chemical Abstracts, Biological Abstracts, Referativnyi Zhurnal and some journals are common to both libraries, but otherwise there is a fairly clear distinction in the subject holdings. It is in any case quite easy to travel from one library to the other.

The stock of the Bayswater Division has been growing since the move to Bayswater in 1966. This was the year the Patent Office library became part of the British Museum and changed its name to the National Reference Library of Science and Invention. The particular emphasis on physical sciences and the associated engineering and industrial tcchnologies at the old Patent Office library was retained, and biological subjects were built up at Bayswater. Some of the stock for Bayswater was bought, but other literature was acquired from the scientific holdings of the British Museum. Although next week's opening will be one milestone in some ways, the literature at Bayswater has not been unavailable since 1966 because it was always possible to consult material from Bayswater in the Holborn Library. This arrangement will stop now, but it is still possible to order and collect from Holborn photocopies of articles from the Bayswater collections.

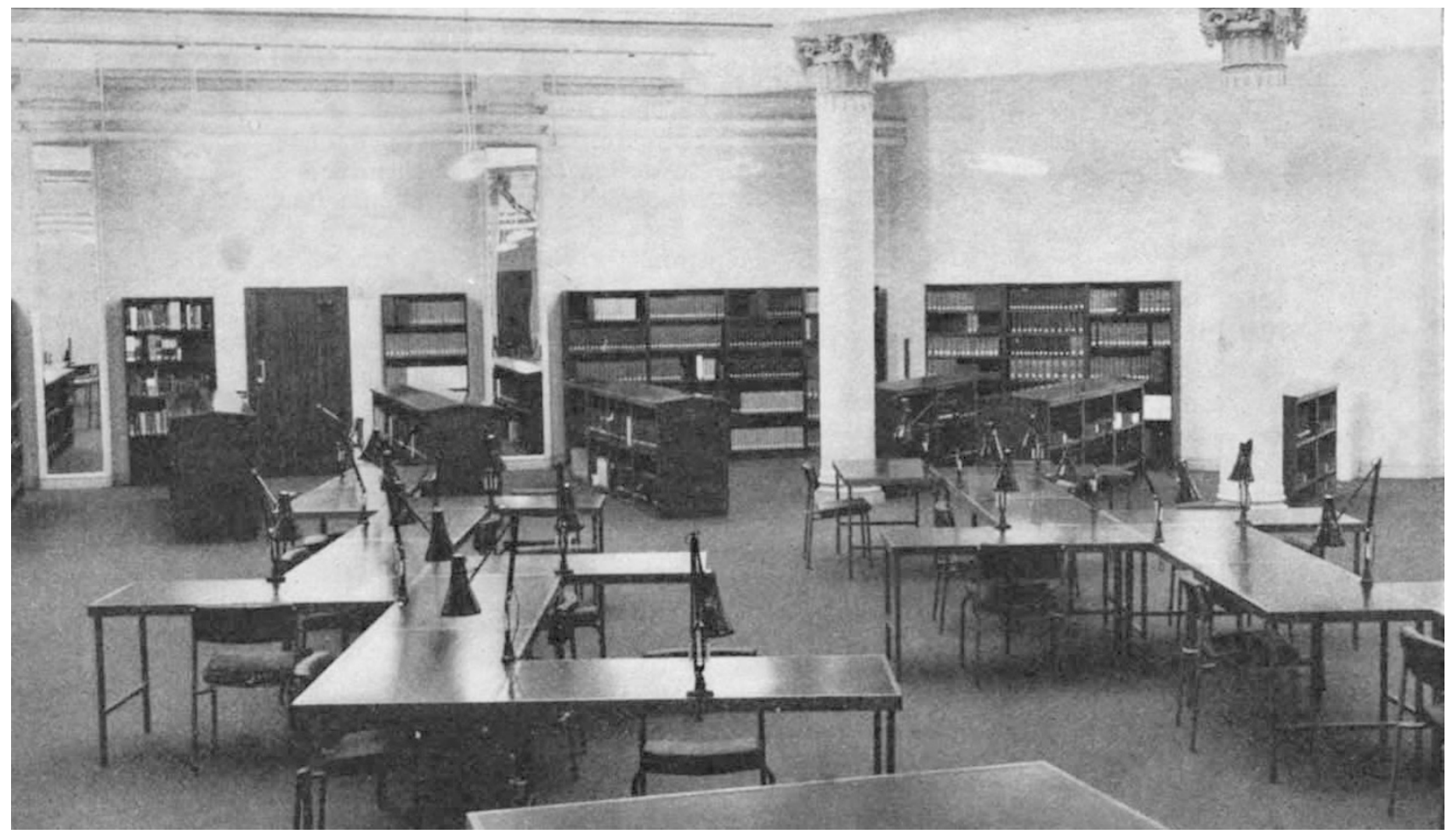

Reading Room in the Bayswater Division of the National Reference Library of Science and Invention. 